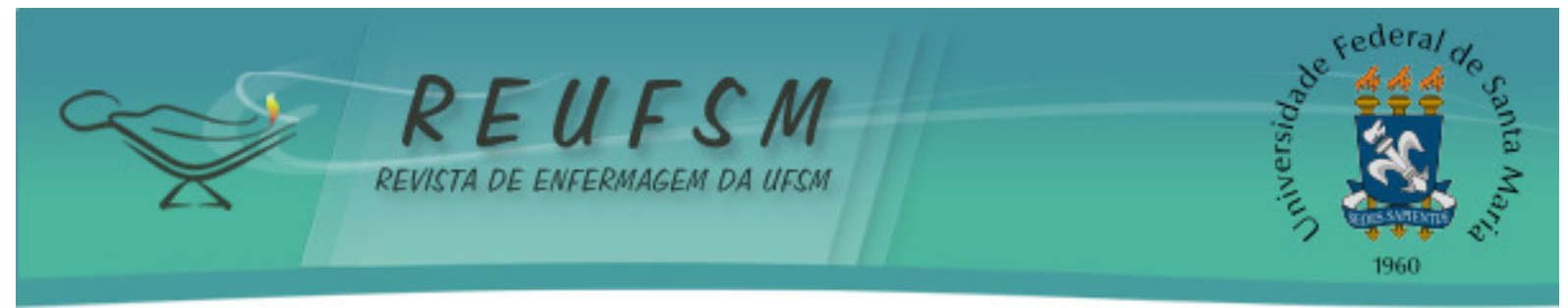

ARTIGO ORIGINAL

\title{
ENFRENTAMENTOS DA CRIANÇA COM CÂNCER FRENTE AO AFASTAMENTO ESCOLAR DEVIDO INTERNAÇÃO HOSPITALAR
}

\author{
COPING OF CHILDREN WITH CANCER ON SCHOOL REMOVAL BECAUSE OF \\ HOSPITALIZATION
}

\section{ENFRENTAMIENTOS DEL NIÑO CON CÁNCER FRENTE AL ALEJAMIENTO DE LA ESCUELA CUANDO HOSPITALIZADO}

\author{
Viviani Viero ${ }^{1}$ \\ Carmem Lúcia Colomé Beck ${ }^{2}$ \\ Paula Hübner Freitas ${ }^{3}$ \\ Alexa Pupiara Flores Coelho ${ }^{4}$ \\ Suzinara Beatriz Soares de Lima $^{5}$ \\ Bruna Parnov Machado ${ }^{6}$
}

Doi: $10.5902 / 2179769210956$

RESUMO: Objetivo: identificar os enfrentamentos de crianças com câncer frente ao afastamento do ambiente escolar devido à internação hospitalar. Método: pesquisa qualitativa, desenvolvida em um Hospital Universitário do interior do estado do Rio Grande do Sul, no período de outubro a novembro de 2007, com o emprego da entrevista semiestruturada com nove crianças, com análise de conteúdo. Resultados: emergiram duas categorias temáticas: "Dificuldades referentes ao desenvolvimento escolar da criança: do diagnóstico ao tratamento", a qual permitiu perceber a influência das restrições impostas pela doença e pelo tratamento na vida escolar e "Apoio e estímulo para a continuidade escolar", na qual foram mencionados os familiares, escola de origem e classe hospitalar. Conclusões: a pesquisa permitiu refletir sobre os enfrentamentos dessas crianças ao se depararem com o afastamento do convívio escolar, sendo relevante os profissionais de enfermagem atentarem para os mesmos, a fim de proporcionar uma assistência integral à esta clientela.

Descritores: Enfermagem; Criança hospitalizada; Oncologia; Escolaridade.

ABSTRACT: Aim: to identify coping of the children with cancer on being removed from school life because of hospitalization. Method: research with a qualitative approach,

\footnotetext{
${ }^{1}$ Enfermeira. Mestranda em Enfermagem pelo Programa de Pós-Graduação em Enfermagem da Universidade Federal de Santa Maria (UFSM). Enfermeira do Hospital Universitário de Santa Maria (HUSM/UFSM). Santa Maria, Rio Grande do Sul, Brasil. E-mail: viviviero@hotmail.com

${ }^{2}$ Enfermeira. Doutora em Enfermagem. Docente do Departamento de Enfermagem da Universidade Federal de Santa Maria (UFSM). Santa Maria, Rio Grande do Sul, Brasil. E-mail: carmembeck@gmail.com

3 Enfermeira. Mestre em Enfermagem pelo Programa de Pós-Graduação em Enfermagem da Universidade Federal de Santa Maria (UFSM). Santa Maria, Rio Grande do Sul, Brasil. E-mail: enf.paulahf@gmail.com

${ }^{4}$ Enfermeira. Mestranda em Enfermagem pelo Programa de Pós-Graduação em Enfermagem da Universidade Federal de Santa Maria (UFSM). Santa Maria, Rio Grande do Sul, Brasil. E-mail: alexa.p.coelho@hotmail.com

${ }^{5}$ Enfermeira. Doutora em Enfermagem. Docente do Departamento de Enfermagem da Universidade Federal de Santa Maria (UFSM). Santa Maria, Rio Grande do Sul, Brasil. E-mail: suzibslima@yahoo.com.br

6 Enfermeira. Mestre em Enfermagem pelo Programa de Pós-Graduação em Enfermagem da Universidade Federal de Santa Maria (UFSM). Coordenadora Adjunta e docente do Curso de Graduação em Enfermagem da Faculdade Integrada de Santa Maria (FISMA). Santa Maria, Rio Grande do Sul, Brasil. E-mail: bruna.machado@fisma.com.br
} 


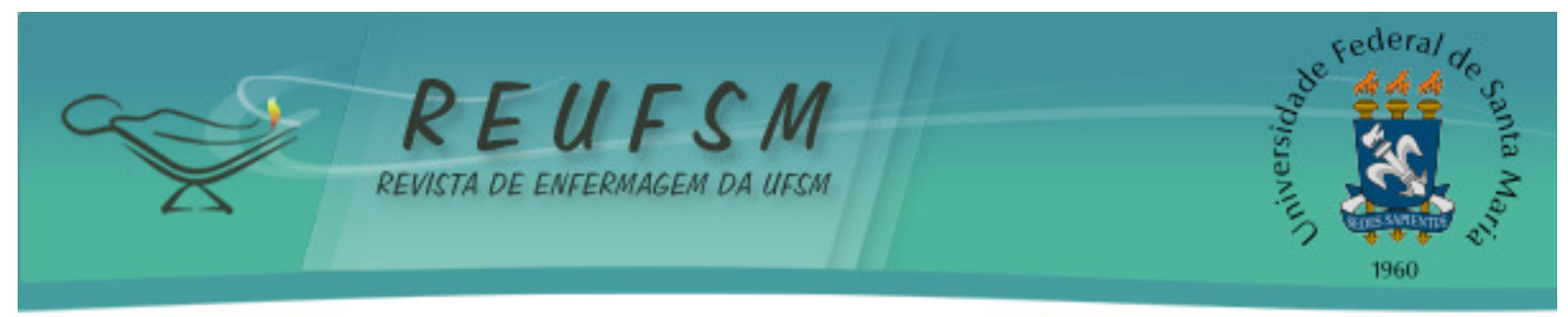

developed in a University Hospital in the state of Rio Grande do Sul, from October to November 2007, with the use of semi structured interviews with nine children and of content analysis. Results: two thematic categories emerged: "Difficulties referred to the child's school performance: of the diagnosis to the treatment" and "Support and stimulus to staying in school", in which it was mentioned the relatives, school of origin and hospital type. Conclusions: thinking about the clashes of these children when across with the removal of the school life is relevant to nursing professionals as also being attention to them, in order to provide comprehensive care to these clients being relevant.

Descriptors: Nursing; Child hospitalized; Medical oncology; Educational status.

RESUMEN: Objetivo: identificar los enfrentamientos de los niños con cáncer frente al alejamiento del ambiente escolar debido a la hospitalización. Método: investigación cualitativa, desarrollada en un hospital universitario en el estado de Rio Grande do Sul, entre Octubre y Noviembre de 2007, usando entrevistas semiestructuradas a nueve niños, y análisis de contenido. Resultados: surgen dos categorías temáticas: "Dificultades referentes al desarrollo escolar del niño: del diagnostico al tratamiento" y "Apoyo y estimulo para la continuidad escolar", en la que fueron mencionados los familiares, escuela de origen y clase hospitalar. Conclusiones: la investigación permitió reflexionar sobre los enfrentamientos de esos niños cuando alejados de la conviviencia escolar, siendo relevante que los profesionales de enfermería estén atentos a ellos, con el fin de brindar una atención integral a esta clientela.

Descriptores: Enfermería; Niño hospitalizado; Oncología médica; Escolaridad.

\section{INTRODUÇÃO}

O câncer, embora seja discutido em termos gerais, não é uma patologia única, mas um conjunto de inúmeras doenças que têm como característica comum o crescimento desordenado das células, o qual pode acometer os mais variados órgão e tecidos. ${ }^{1}$ Pode surgir em qualquer faixa etária, em ambos os sexos e ter diferentes causas, manifestações, tratamentos e prognósticos, ocasionando medo, sofrimento e angústia ao sujeito e sua família.

o câncer infantil apresenta características muito específicas e origens histopatológicas próprias, diferentes do câncer no adulto, principalmente no que diz respeito ao comportamento clínico. Esse grupo de neoplasias, em geral, apresenta curtos períodos de latência, é mais agressivo e cresce rapidamente, contudo responde melhor ao tratamento e é considerado de bom prognóstico. ${ }^{1}$

Estimativas apontam que o câncer na criança e no adolescente corresponde de $1 \%$ a $3 \%$ de todos os tumores malignos na maioria das populações, o que leva a uma estimativa de 11.530 casos novos para o ano de 2012, válida também para o ano de 2013. Os óbitos por câncer para a faixa etária de um a 19 anos encontraram-se entre as dez principais causas de morte no Brasil, sendo que, a partir dos cinco anos de idade, a morte por câncer é considerada como a primeira causa de morte por doença em ambos os sexos. ${ }^{1}$

Frente a esses dados, percebe-se que a criança é um ser vulnerável ao desenvolvimento desta patologia e vivencia os fatores desgastantes e estressores do tratamento instituído, o qual exige hospitalizações frequentes e prolongadas, capazes de debilitar física e emocionalmente o paciente.

Somam-se a isso as alterações da imagem corporal quase sempre presentes como a alopecia, ganho de peso, lesões e tumores aparentes, mutilações, cicatrizes, uso de cateteres venosos, dentre outras, ${ }^{2}$ as quais podem contribuir para a baixa autoestima, para a perda do reconhecimento e do convívio com seu grupo social.

Deste modo, a identidade de ser criança pode ser esquecida no processo de 


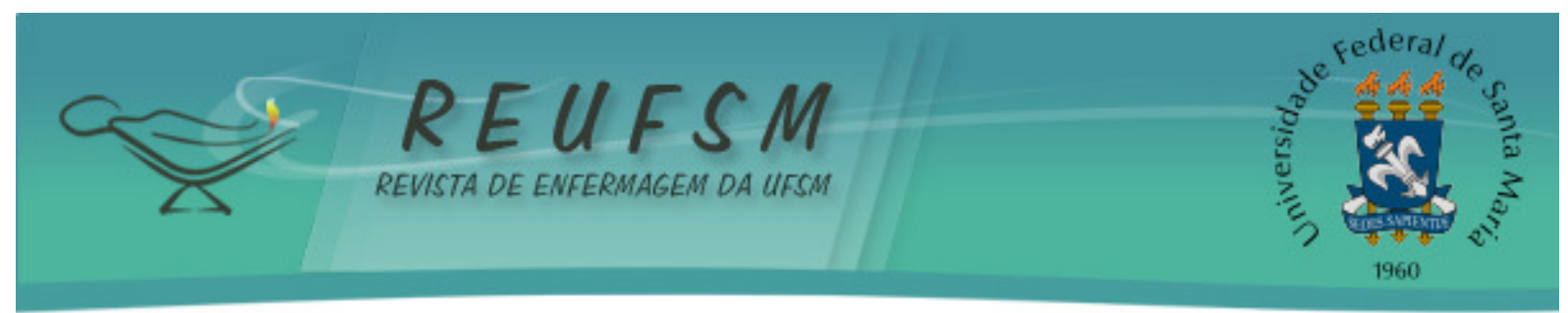

internação, tendo em vista que ela vivencia uma realidade diferente do seu cotidiano e passa a ser tratada apenas como mais um paciente. Na realidade hospitalar, realizam-se uma série de procedimentos na criança, muitas vezes, tratando-a como um mero depositário de cuidados e não se considerando que ela tenha um papel ativo e fundamental na condição de sua própria existência. ${ }^{2}$

Assim, por entender a importância de reconhecer a criança como um ser que possui necessidades singulares de acordo com sua faixa etária e não somente limitações e restrições impostas pela doença e tratamento, evidencia-se que o desenvolvimento desta, mesmo estando doente, continua ocorrendo e, por isso, deve prosseguir sendo estimulada a brincar, estudar, questionar e realizar tudo o que uma criança saudável realiza.

É preciso considerar que, além de carregar o estigma do câncer, a criança quando hospitalizada deixa de vivenciar situações importantes para o desenvolvimento humano, como por exemplo, a interação escolar com colegas e professores. Nesse sentido, acredita-se que os profissionais que atuam nesse contexto devem desenvolver competências especiais como o estímulo lúdico e o apoio aos seus familiares na intenção de orientá-los a este respeito.

A oferta de ações educacionais para a criança enferma é um grande avanço, já que, por meio da relação entre a família, a equipe de saúde e a equipe educacional, é propiciada a continuidade de um projeto de vida e a busca da sua realização. No entanto, trata-se, também, de um desafio que envolve, com igual intensidade, esforços de profissionais da saúde e da educação, pois, embora instâncias oficiais e organizações civis reconheçam esse direito, ainda se faz necessário ativar outros mecanismos sociais para que seja realmente concretizado. ${ }^{3}$

Neste sentido, é resguardado à criança o direito de desfrutar de alguma forma de recreação, de programas de educação para a saúde e do acompanhamento do currículo escolar durante a internação hospitalar, pois se entende que a criança inserida no hospital precisa se adaptar, principalmente, ao afastamento da escola e de seus amigos, o que, muitas vezes, pode interferir na aderência ao tratamento. ${ }^{4}$

Portanto, justifica-se a realização da pesquisa, pois se percebe que esta problemática é pouco observada em estudos da enfermagem, como se evidencia em uma revisão integrativa de literatura sobre cuidados de enfermagem à criança com câncer, na qual não há menção direta sobre o aspecto educacional destas. ${ }^{5}$ Além disso, na perspectiva da criança, observa-se empiricamente que a não continuidade escolar pode ser um fator que impacta no processo de saúde e doença.

Deste modo, elencou-se como questão norteadora da pesquisa: Quais os enfrentamentos vivenciados por crianças em tratamento oncológico, decorrentes do afastamento do ambiente escolar?

Por fim, o objetivo geral foi identificar os enfrentamentos de crianças com câncer frente ao afastamento do ambiente escolar, devido a internação hospitalar para o tratamento da doença.

\section{MÉTODO}

Trata-se de uma pesquisa do tipo exploratório-descritivo, com abordagem qualitativa. 0 método qualitativo aplica-se ao estudo da história, das representações, das relações, das crenças, das percepções e opiniões, produtos de interpretações que os humanos realizam sobre como vivem, estabelecem seus artefatos e a si mesmos, sentem e pensam. ${ }^{6}$

0 cenário da pesquisa foi o Centro de Tratamento de Crianças e Adolescentes com Câncer (CTCriaC) de um Hospital Universitário do interior do estado do Rio Grande do Sul, Brasil.

Os participantes da pesquisa foram selecionados a partir dos seguintes critérios de 


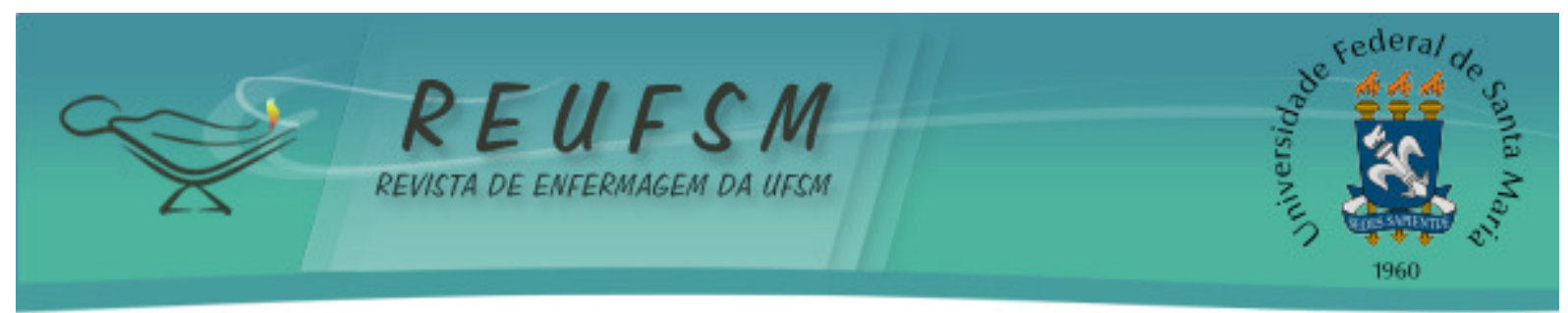

inclusão: estar na faixa etária entre nove e 12 anos de idade, tendo em vista que estas responderão com maior entendimento a entrevista; ter diagnóstico confirmado de doença oncológica e estar em tratamento; ter condições físicas e emocionais de participar da pesquisa, juntamente com o assentimento desta e a concordância do familiar ou cuidador responsável. A amostra final foi composta por nove crianças, as quais atendiam a estes critérios, sendo recrutadas conforme internavam na unidade até atingir-se a saturação dos dados $^{7}$ e o alcance dos objetivos propostos.

O período de coleta de dados foi de 30 de outubro a 30 de novembro de 2007, sendo utilizada como técnica, a entrevista semiestruturada. A entrevista foi composta por questões norteadoras, previamente definidas pela pesquisadora, concernentes à temática e adequadas ao entendimento das crianças e pelo preenchimento de um questionário sóciodemográfico, abordando questões como sexo, idade, procedência, diagnóstico e dados referentes ao desempenho escolar.

$\mathrm{Na}$ análise dos dados, primeiramente, foi realizada uma caracterização das crianças participantes da pesquisa. Para isso, utilizou-se a estatística descritiva ${ }^{8}$ e os dados foram apresentados em percentuais, junto a discussão com a literatura especializada no tema. Em um segundo momento, as falas dos sujeitos foram analisadas por meio da análise de conteúdo, compreendendo três etapas distintas: a pré-análise, a exploração do material, o tratamento dos resultados obtidos e interpretação, buscando a construção de categorias temáticas representativas do fenômeno estudado. ${ }^{6}$

Em relação aos aspectos éticos, o projeto de pesquisa foi aprovado pelo Comitê de Ética em Pesquisa (CEP) da Universidade Federal de Santa Maria (UFSM) em 24 de outubro de 2007 com identificação da CAAE (Certificado de Apresentação para Apreciação Ética) $n^{\circ}$ 0155.0.243.000-07.

O Termo de Consentimento Livre e Esclarecido (TCLE) foi assinado em duas vias pelos responsáveis das crianças participantes, respeitando-se os preceitos éticos e legais necessários à realização de pesquisas com seres humanos, conforme preconiza a Resolução 196/96 do Conselho Nacional de Saúde. ${ }^{9}$

Não foram utilizados gravadores, filmadoras ou máquinas fotográficas, somente o registro escrito das respostas, tendo em vista a especificidade do grupo investigado. Com o intuito de garantir a privacidade dos sujeitos e a confidencialidade dos dados, as falas das crianças foram identificadas por cores durante a apresentação dos resultados. A maioria das crianças participantes foi abordada no próprio leito de internação, porém a entrevista foi conduzida em local apropriado para garantir a privacidade destas, sendo que permaneceram na companhia dos familiares e/ou cuidadores responsáveis.

\section{RESULTADOS E DISCUSSÃO}

A pesquisa contou com a participação de nove crianças na faixa etária de nove a 12 anos de idade. Quanto ao sexo, a maioria dos entrevistados $(77,7 \%)$ era do sexo feminino, sendo que este achado diverge de estudos que abordam que a incidência total de tumores malignos na infância é maior no sexo masculino. ${ }^{1,10}$ Contudo, não se pode esquecer que diversos outros fatores estão ligados à etiologia e incidência do câncer e que a amostra de participantes foi pequena.

Em relação à procedência dos entrevistados, foram citadas as cidades de Caçapava do Sul, Alegrete, Arroio Grande, Santana do Livramento, Cacequi, Santo Ângelo, Maçambará e Bagé, sendo que nesta última localidade residiam duas das nove crianças respondentes. Este dado demonstra a abrangência regional do Hospital Universitário como centro de referência para tratamentos de alta complexidade, em especial, para o tratamento hemato-oncológico pediátrico. 


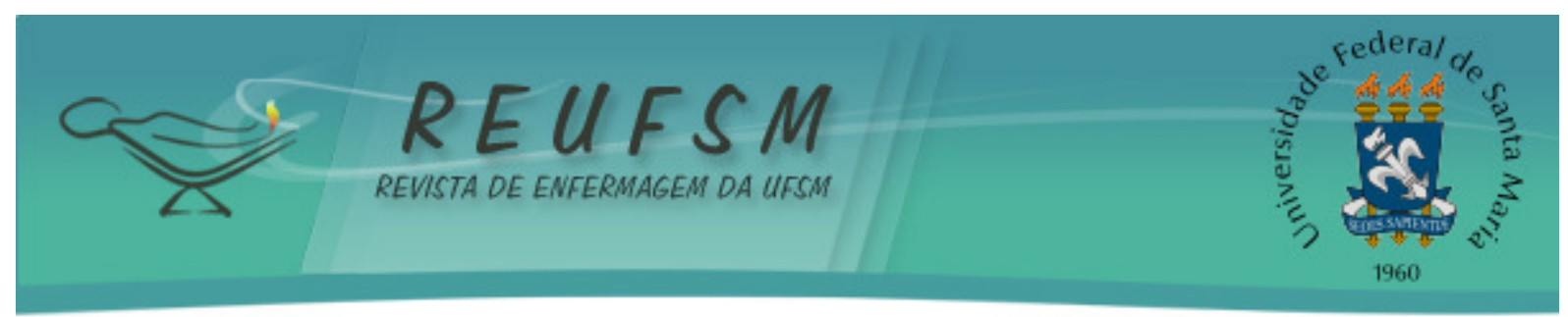

A maioria das crianças, isto é, $66,6 \%$, relataram que residiam com os pais (mãe e pai) e com seus irmãos e $33,3 \%$ apenas com a mãe e os irmãos. Todas as crianças entrevistadas possuíam irmãos e uma mencionou que a avó morava junto e ajudava a cuidá-la.

A família é o primeiro e principal grupo em que o ser humano está inserido desde o nascimento, portanto, pode-se dizer que o âmbito familiar é um mundo de relações que pode até mesmo implicar na luta pela cura da doença, pois o amor, o carinho e o apoio dados renovam o ânimo da pessoa doente. ${ }^{11}$ Assim, salienta-se a importância da família para a criança doente como cuidadora e estimuladora, sendo fundamental sua presença e colaboração.

Ressalta-se também que a doença afeta a família como um todo, não apenas o paciente e, portanto, todos terão a possibilidade de terem suas vidas alteradas de maneira mais ou menos sutil ou significativa ao longo do curso da doença. Ao se falar em família, esta é definida interativamente mais do que biologicamente e, assim sendo, refere-se a um círculo com o qual o paciente interage, troca informações e está ligado por vínculos fortes, pessoais, recíprocos ou obrigatórios, no qual podem ser incluídos todos que se envolverem no processo de tratamento. ${ }^{11}$

Quanto aos diagnósticos médicos, obtiveram-se cinco diagnósticos distintos, sendo que dentre estes, a Leucemia Linfocítica Aguda (LLA) foi a mais frequente $(44,4 \%)$. Este achado corrobora com o que evidenciam estudos na temática ${ }^{1-2,10,12}$, os quais referem que as leucemias são as neoplasias mais comuns na infância. Também apareceram como diagnósticos o Sarcoma de Ewing, Leucemia Juvenil, Tumor de Wilms e tumor de ovário.

O tempo de tratamento dos entrevistados variou de três meses a dois anos e quatro meses, considerando-se o diagnóstico médico e as recidivas da doença, sendo necessário retomar ou iniciar um novo tratamento. Conforme os dados coletados, houve recidivas em três das crianças entrevistadas, coincidindo com as que apresentaram um maior tempo de tratamento.

Ressalta-se que o tratamento das doenças oncológicas infantis, principalmente das leucemias, é baseado em protocolos que possuem diversas fases, almejando a remissão da doença. Essas fases envolvem a administração de quimioterápicos por distintas vias, tanto em regime de internação quanto ambulatorial, podendo ter duração de anos. ${ }^{13}$ Assim, este longo período de tratamento pode se caracterizar como um fator gerador de trauma e desgaste para as crianças e seus familiares, coincidindo também como um dos entraves para o convívio escolar.

Em relação à escolaridade, observou-se que quatro crianças encontravam-se na $1^{\text {a }}$ série do ensino fundamental $(44,4 \%)$, estando as demais divididas nas outras séries (da $2^{\mathrm{a}}$ à $6^{\text {a }}$ série). Quanto a repetição de anos escolares, a maioria das crianças respondentes $(66,6 \%)$ afirmou que tiveram repetição. Destas, cinco crianças repetiram um ano escolar e uma criança dois anos escolares. Apenas três crianças não tiveram repetência escolar.

Em relação ao motivo da repetição, as seis crianças que repetiram anos escolares referiram a hospitalização e a doença como causas principais. Entre outras razões, também citaram dificuldades de aprendizagem já existentes antes do surgimento da doença e do tratamento, mas que se agravaram com a não continuidade da frequência na escola.

Estes dados vão ao encontro do que mostra um estudo sobre a escolarização de crianças hospitalizadas com condições crônicas, o qual apontou o atraso escolar destas, devido a perda de conteúdos e os afastamentos regulares da escola, motivados pelas frequentes internações. ${ }^{14}$

Isto se mostra importante, pois destaca a relação entre a doença e o tratamento, visto que as medicações utilizadas na terapêutica e a ausência de desafios cognitivos decorrentes da reclusão hospitalar podem acarretar regressão de várias áreas do sistema 


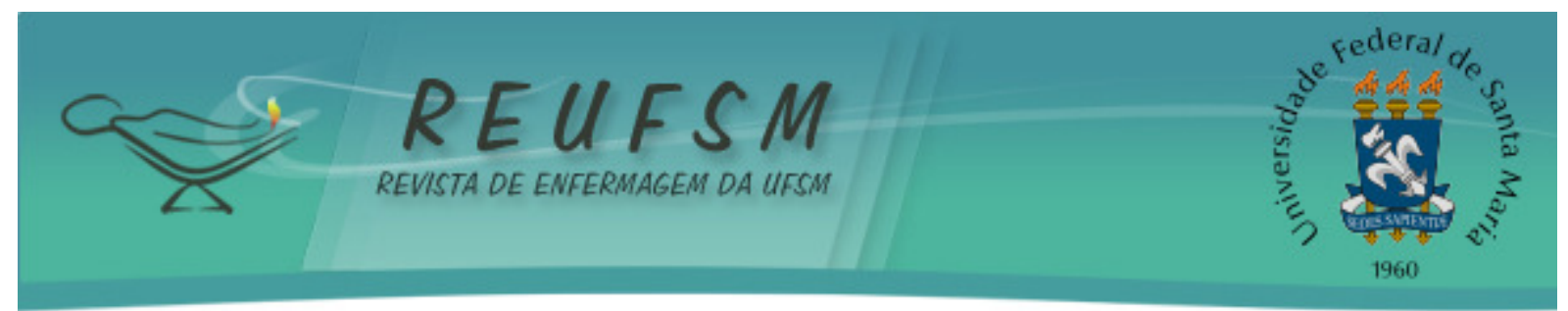

nervoso central, tal como memória, concentração, atenção, coordenação motora fina, linguagem e inteligência, podendo ocasionar distúrbios da aprendizagem. ${ }^{15}$ Destarte, pode haver o atraso na aprendizagem, sendo esta uma realidade observada durante a pesquisa.

Quanto as categorias que emergiram do estudo destacam-se duas, quais sejam: "Identificando as dificuldades referentes ao desenvolvimento escolar: do diagnóstico ao tratamento" e "Recebendo apoio e estímulo para a continuidade escolar". No que tange à categoria Identificando as dificuldades referentes ao desenvolvimento escolar: do diagnóstico ao tratamento, as crianças relataram acerca das internações e restrições do ambiente hospitalar, que:

O início foi difícil, fiquei muito tempo internada... era tudo novo $e$ só veio a mãe comigo [...] sinto falta de brincar. (Rosa)

Entende-se que a doença e a hospitalização na infância representam uma experiência ameaçadora para a criança que, privada de seu cotidiano, se percebe em um ambiente diferente, sendo obrigada a se separar de sua família, de seus amigos, de sua escola e de seus objetos significativos. ${ }^{14}$

Ao serem questionados se o diagnóstico e o tratamento prejudicavam o desenvolvimento escolar, identificou-se que $88,8 \%$ das crianças sentiram-se prejudicadas devido a impossibilidade de frequentarem a escola regular naquele período, apontando as internações hospitalares, o mal-estar devido ao uso dos quimioterápicos e a falta de continuidade do acompanhamento do ano letivo.

As crianças referiram mal-estar físico e alterações na imagem corporal devido ao tratamento que, geralmente, continua no domicílio e em atendimento ambulatorial, e a perda da sequência escolar devido a consultas frequentes e possíveis reinternações. Foi ressaltada a falta da presença diária do professor e dos colegas no processo ensinoaprendizagem. Esses dados evidenciam-se nas falas abaixo:

Fui liberada para ir na aula dois dias, mas tenho que ficar numa sala separada dos meus colegas [...] o mais ruim é que fiquei mais gorda por causa dos comprimidos e tenho que usar uma máscara para me proteger... todo mundo fica me olhando lá. (Verde)

[...] quando meu cabelo começou a cair, que eu fiquei careca, fiquei triste e não queria mais sair de casa, nem ir na aula. (Amarelo)

Às vezes, não estou bem para ir na escola, tenho vontade de vomitar. (Vermelho)

Pelas falas, é possível notar que a alteração da imagem corporal incomoda porque desperta a atenção e o olhar das outras pessoas que a acham diferente, o que a desmotiva de continuar estudando, assim como o mal estar físico ocasionado pelo tratamento pode se constituir, também, uma barreira nesse processo.

As alterações da imagem corporal decorrentes do tratamento quimioterápico, tais como a alopecia e a alteração de peso, são evidenciadas por estudos como fatores significativos e limitantes no universo de crianças e adolescentes com câncer. ${ }^{16}$ Em relação a esta colocação, salienta-se que a aparência física, a inadaptação motora agravada pela limitação da vivacidade e do vigor, resultantes dos efeitos colaterais das medicações empregadas, podem constituir-se em barreiras para a livre incorporação da criança no universo educativo. ${ }^{15}$ 


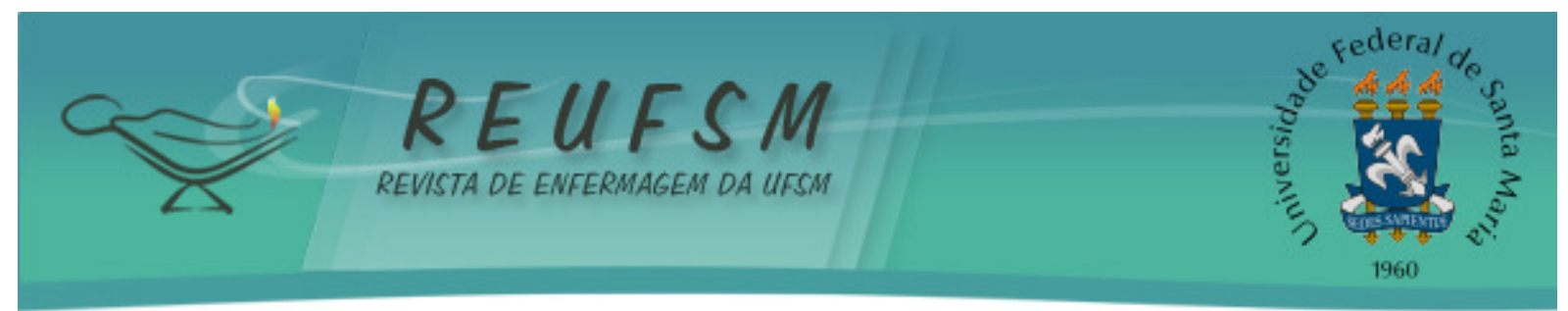

Neste sentido, percebe-se que a existência da doença, as internações repetidas e a autoimagem prejudicada geram dificuldades nos relacionamentos dessas crianças no contexto social em que estão inseridas, sobretudo no tocante aos relacionamentos na escola com outros colegas. Evidencia-se também que o preconceito pode induzir ao isolamento social. ${ }^{17}$

Além disso, estas crianças são, muitas vezes, orientadas a não frequentar a escola regular em decorrência das restrições da própria doença e do tratamento realizado, tendo que continuar estudando em casa o que é, para alguns, desmotivante, como se revela na fala de um dos entrevistados:

Não posso ir na escola e não gosto de estudar em casa. (Azul)

Assim sendo, o apoio e o estímulo para a continuidade escolar se mostram importantes, estando tanto a equipe de saúde quanto a educacional inseridas neste contexto.

$\mathrm{Na}$ categoria Recebendo apoio e estímulo para a continuidade escolar, quando questionados se recebiam apoio para a continuidade escolar, todos se manifestaram positivamente, sendo que os principais agentes apontados foram os familiares, os professores e diretores das escolas de origem e a classe hospitalar que presta atendimento pedagógico às crianças internadas, como se evidencia nas falas:

\section{Sim, da minha professora e da diretora do colégio. (Rosa)}

Quem sempre me ajuda é minha mãe e as tias lá do hospital [se referindo à classe hospitalar]. (Branco)

Nesta perspectiva, ressalta-se a importância e o direito do atendimento escolar para crianças em tratamento de saúde o qual, no presente cenário de pesquisa, é suprido pela Classe Hospitalar vinculada ao Projeto de Extensão “Educação e Saúde: uma proposta para o serviço de Hemato-Oncologia", desenvolvido no Hospital Universitário de Santa Maria (HUSM).

Define-se como classe hospitalar o atendimento pedagógico-educacional que ocorre em ambientes de tratamento de saúde, principalmente na circunstância de internação, o qual contribui para a inclusão e humanização da assistência hospitalar. ${ }^{18}$

Portanto, as relações de aprendizagem escolar no ambiente hospitalar são "injeções de ânimo", pois por meio dessa, a criança manterá um vínculo com seu mundo fora do hospital, proporcionando o seu desenvolvimento cognitivo, intelectual e sua formação social, além de dar continuidade ao currículo escolar, visando diminuir o desestímulo pelo estudo e evitando a evasão escolar. ${ }^{19}$

Ao ser indagado se a escola de origem e os professores estavam cientes da doença dos seus alunos, todas as crianças (100\%) afirmaram que sim. Também, todos os participantes referiram que a escola e os professores procuraram ajudar na continuidade das atividades escolares por meio do acompanhamento domiciliar, sendo que a maioria recebia os conteúdos didáticos e trabalhos em casa, ou os familiares buscavam com os professores, realizando avaliações programadas na escola.

Neste contexto, é importante ressaltar que mesmo não estando internada, se por algum motivo especial a criança não puder frequentar a escola regular junto com seus colegas, esta pode e deve continuar seu aprendizado em seu domicílio, com a ajuda dos professores e direção da escola de origem, a partir do atendimento pedagógico domiciliar, até poder novamente frequentar o ambiente escolar. ${ }^{18}$

Mesmo que as exigências do tratamento se configurem em limites à escolarização, 


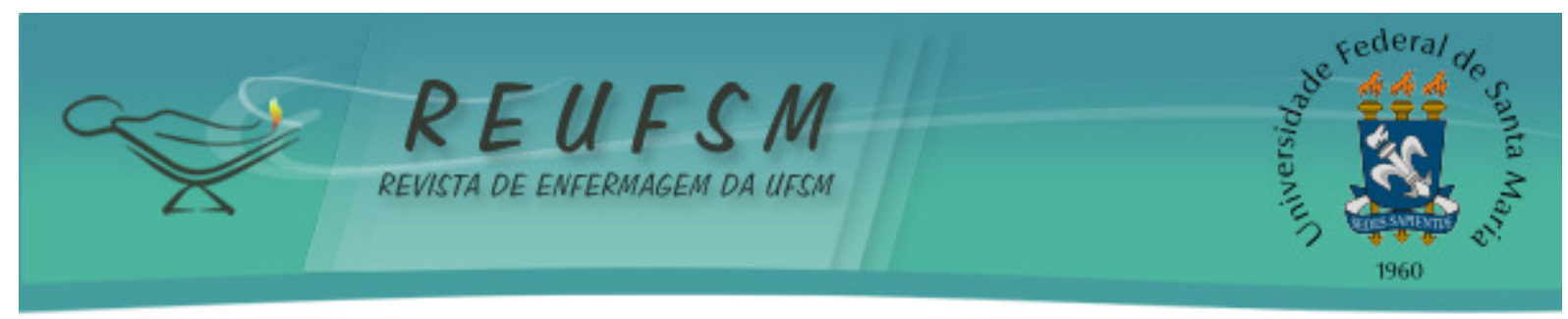

é fundamental que a escola redirecione seu fazer, garantindo a flexibilização como um modo de priorizar o desempenho da escolaridade e a continuidade da terapêutica, em detrimento das suas rotinas organizacionais. ${ }^{15}$ Isto pode ser considerado uma realidade no acompanhamento às crianças participantes, entretanto, apesar do apoio recebido, a descontinuidade escolar e repetição de anos escolares mostraram-se presentes.

Nesta perspectiva, reitera-se a importância do vínculo entre a escola e o ambiente hospitalar, com vistas a promover a continuidade do processo de escolarização da criança em condição crônica, respeitando-a em seus direitos e garantindo-lhe o exercício de sua cidadania. Isto se justifica, pois, além dos constrangimentos vivenciados no seu cotidiano, as perdas escolares decorrentes das restrições inerentes à doença crônica na infância podem vir a desencadear muitos problemas na vida adulta. ${ }^{17}$ Para tanto, mostra-se importante a interação e comunicação eficaz entre a família, o hospital e a escola, a fim de facilitar o processo de reinserção escolar dessas crianças. ${ }^{14}$

Deste modo, foi possível evidenciar os enfrentamentos que a criança com câncer em idade escolar se depara no decorrer do seu tratamento e que a terapêutica agressiva característica do tipo de doença e as internações hospitalares prejudicam o bom desenvolvimento escolar, o que foi notado pelo número de repetições escolares apresentadas.

Todavia, este não é um fator único, tendo em vista que a vida destas crianças configura um cenário de marcantes limitações. Há restrições relativas aos processos orgânicos determinados pela doença, contudo muitas das perdas são causadas pela cultura, a qual transforma o doente em sua doença e o vê em suas impossibilidades, ao invés de valorizar suas potencialidades. ${ }^{3}$

Assim, é preciso ressaltar que esta não é uma regra geral que pode ser aplicada a todas as crianças em tratamento contra o câncer, pois depende muito do tipo de doença, da fase do tratamento, do apoio recebido e da compreensão dos educadores envolvidos no processo. Além disso, é imprescindível a colaboração da equipe de saúde, especialmente da enfermagem, que também deve estar ciente destas dificuldades e procurar estimular a continuidade escolar, a fim de contribuir num cuidado verdadeiramente humanizado e integral em oncologia pediátrica.

\section{CONSIDERAÇÕES FINAIS}

O câncer e seu tratamento invasivo, assim como as internações hospitalares, foram apontados pelas crianças participantes como barreiras para continuarem estudando normalmente.

A realização deste estudo possibilitou refletir acerca da importância da escola para a criança e seu imaginário infantil, principalmente para desmistificar o rótulo de "criança com câncer", vista e tratada apenas como um paciente que necessita de cuidados de saúde, sendo esquecida como criança e não estimulada a manter suas atividades normais, como brincar e estudar.

É preciso lembrar que a criança doente não deixa de ser criança e que seu desenvolvimento prossegue ocorrendo mesmo estando debilitada do ponto de vista clínico e internada em um hospital. Portanto, deve ser estimulada continuamente a estudar, já que a escola, além de um ambiente de encontro e troca com seus pares, é também onde se adquire e se desenvolve inúmeras habilidades e competências necessárias e essenciais à vida adulta.

Portanto, é fundamental procurar meios de tornar a continuidade escolar uma realidade para todas as crianças, sendo imprescindível a colaboração dos envolvidos no cuidado a estas, ou seja, tanto da equipe de saúde quanto educacional, visto que todos são responsáveis pelo futuro das mesmas. 


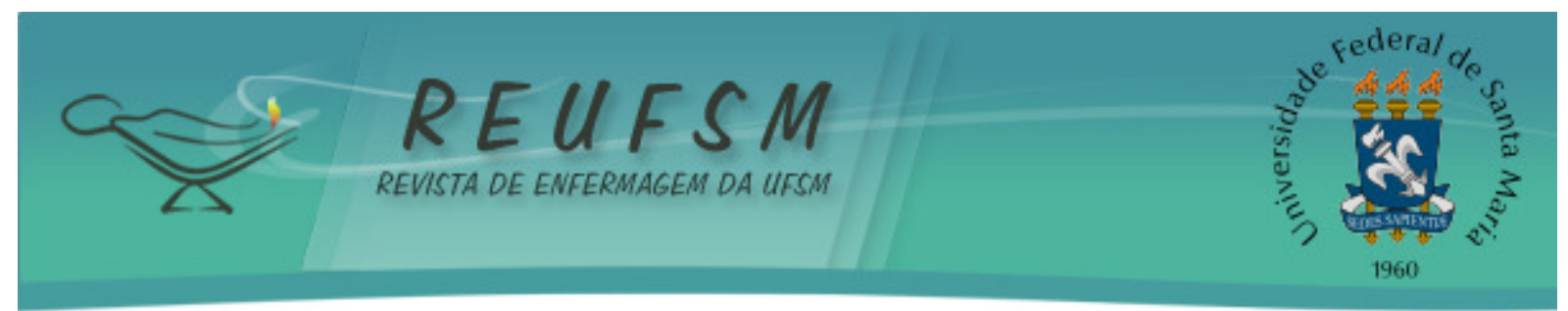

Deste modo, observa-se que é necessário que os profissionais de enfermagem inseridos neste contexto tenham sensibilidade e conhecimento para lidar com diferentes experiências culturais e com a diversidade humana, identificando as necessidades educacionais das crianças e estando dispostos a modificar e adaptar os processos de cuidar. Estes devem buscar estimular a continuidade escolar por meio de uma comunicação efetiva com a criança e sua família, utilizando a educação em saúde como forma de prepará-los e orientá-los neste processo.

É necessário que os profissionais estejam capacitados a enfrentar as situações de cuidado que estas crianças exigem, destacando-se a necessidade de se preocupar não só com o corpo do indivíduo hospitalizado, superando-se as práticas centradas em intervenções tecnicistas, mas também numa perspectiva de atenção integral, almejando um cuidado cada vez mais humanizado e alicerçado nas singularidades da clientela em questão.

Destaca-se como relevância deste tema, a enfermagem estar atentando para outros aspectos do cuidado a criança, como o educacional, a fim de auxiliar na redução da evasão escolar em decorrência do tratamento oncológico instituído. Entretanto, aborda-se como limitações deste estudo, o reduzido número de participantes e o fato de ter sido realizado em apenas um cenário de estudo, sendo recomendada a ampliação deste.

\section{REFERÊNCIAS}

1. Brasil. Ministério da Saúde. Instituto Nacional de Câncer José Alencar Gomes da Silva (Inca). Estimativa 2012: incidência de câncer no Brasil [Internet]. 2011 [acesso em 2012 jun 20]. Disponível em: http://www.inca.gov.br/estimativa/2012.pdf.

2. Oliveira T, Figueiredo NMA, Marques PA, Melo ECP, Silva LR, Nascimento MAL, et al. A criança com câncer no hospital. IN: Figueiredo NMA, Leite JL, Machado WCA, Moreira MC, Tonini T, organizadores. Enfermagem oncológica: conceitos e práticas. $1^{\text {a }}$ ed. São Caetano do Sul, SP: Yendis Editora; 2009. p. 269-91.

3. Rolim CLA, Goes MCR. Crianças com câncer e o atendimento educacional nos ambientes hospitalar e escolar. Educ Pesqui [Internet]. 2009 [acesso em 2013 mar 20];35(3):509-23. Disponível em: http://www.scielo.br/pdf/ep/v35n3/07.pdf.

4. Brasil. Conselho Nacional dos Direitos da Criança e do Adolescente. Resolução $n^{\circ} 41$, de 13 de outubro de 1995. Aprova em sua íntegra o texto oriundo da Sociedade Brasileira de Pediatria, relativo aos Direitos da Criança e do Adolescente Hospitalizados [Internet]. 1995 out [acesso em 2013 jul 10]. Disponível em: http://www.ufrgs.br/bioetica/conanda.htm.

5. Silva TP, Leite JL, Santos NLP, Silva IR, Mendonça ACA, Santos MJC, et al. Cuidados de enfermagem à criança com câncer: uma revisão integrativa da literatura. Rev Enferm UFSM [Internet]. 2013 jan/abr [acesso em 2013 jul 21];3(1):68-78. Disponível em: http://cascavel.ufsm.br/revistas/ojs-2.2.2/index.php/reufsm/article/view/6918.

6. Minayo MCS. O desafio do conhecimento: pesquisa qualitativa em saúde. $12^{a}$ ed. São Paulo: Hucitec; 2010.

7. Fontanella BJB, Ricas J, Turato ER. Amostragem por saturação em pesquisas qualitativas em saúde: contribuições teóricas. Cad Saúde Pública. 2008;24(1):17-27.

8. Lakatos EM, Marconi, MA. Fundamentos da metodologia científica. São Paulo: Atlas, 2005.

9. Brasil. Ministério da Saúde. Conselho Nacional de Saúde. Resolução CNS n 196, de 10 de outubro de 1996. Aprova diretrizes e normas regulamentadoras de pesquisas envolvendo 


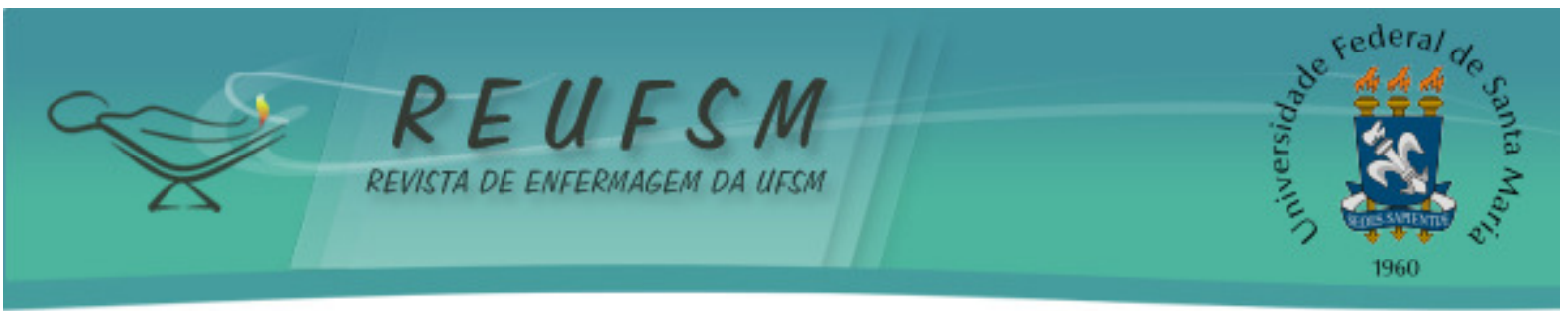

seres humanos [Internet]. 1996 out [acesso em 2012 jun 10]. Disponível em: http: / /www.datasus.gov.br/conselho/resol96/RES19696.htm.

10. Reis RS, Santos MO, Thuler LCS. Incidência de tumores pediátricos no Brasil. Rev Bras Cancerol [Internet]. 2007 [acesso em 2013 jun 10];53(1):5-15. Disponível em: http://www.inca.gov.br/rbc/n_53/v01/pdf/artigo1.pdf.

11. Ceolin VES. A família frente ao diagnóstico do câncer. In: Silva MR, Paraiba $M$, coordenadores. Câncer: uma abordagem psicológica. Porto Alegre, RS: AGE; 2008. p. 118-28.

12. Amador DD, Gomes IP, Coutinho SED, Costa TNA, Collet N. A vivência do cuidado em oncologia pediátrica e a busca pela produção do conhecimento. Rev Enferm UFPE [Internet]. 2010 abr-jun [acesso em 2012 abr 5];4(2):666-72. Disponível em:http://www.revista.ufpe.br/revistaenfermagem/index.php/revista/article/viewFile/8 51/pdf_53.

13. Rodrigues DB, Duarte AM. Neoplasias onco-hematológicas infantis. In: Passos P, Crespo A. Enfermagem oncológica antineoplásica. 1a ed. São Paulo: Lemar; 2011. p. 223-47.

14. Holanda ER, Collet N. Escolarização da criança hospitalizada sob a ótica da família. Texto \& Contexto Enferm [Internet]. 2012 jan-mar [acesso em 2013 jun 10];21(1):34-42. Disponível em: http://www.redalyc.org/pdf/714/71422299004.pdf.

15. Ortiz LCM, Freitas SN. Classe hospitalar: caminhos pedagógicos entre saúde e educação. Santa Maria: Ed. UFSM; 2005.

16. Cicogna EC, Nascimento LC, Lima RAG. Crianças e adolescentes com câncer: experiências com a quimioterapia. Rev Latino am Enferm [Internet]. 2010 set-out [acesso em 2013 mar 25];18(5):[cerca de 9 p.]. Disponível em: http://www.redalyc.org/pdf/714/71422299004.pdf.

17. Nóbrega RD, Collet N, Gomes IP, Holanda ER, Araújo YB. Criança em idade escolar hospitalizada: significado da condição crônica. Texto \& Contexto Enferm [Internet]. 2010 jul-set [acesso em 2013 jun 10];19(3):425-33. Disponível em: http://www.scielo.br/pdf/tce/v19n3/a03v19n3.pdf.

18. Brasil. Ministério da Educação. Classe hospitalar e atendimento pedagógico domiciliar: estratégias e orientações [Internet]. Brasília: MEC, Secretaria de Educação Especial; 2002 [acesso em 2013 jul 21]. Disponível em: http://portal.mec.gov.br/seesp/arquivos/pdf/livro9.pdf.

19. Gomes JO, Rubio JAS. Pedagogia hospitalar: a relevância da inserção do ambiente escolar na vida da criança hospitalizada. Rev Eletrônica Saberes da Educação [Internet]. 2012 [acesso em 2013 jul 21];3(1):1-13. Disponível em: http://www.facsaoroque.br/novo/publicacoes/pdf/v3-n1-2012/Janaina.pdf.

Data de recebimento: $13 / 10 / 2013$

Data de aceite: $21 / 02 / 2014$

Contato com autor responsável: Viviani Viero

Endereço Postal: Avenida João Machado Soares, 856. Camobi, Santa Maria/RS. CEP 97110-000.

E-mail: viviviero@hotmail.com 